\title{
Healthcare information for all
}

\author{
Together, we can stop people dying from a lack of timely accurate healthcare information
}

\author{
Neil Pakenham-Walsh HIFA coordinator ${ }^{1}$, Fiona Godlee editor in chief $^{2}$ \\ ${ }^{1}$ Global Healthcare Information Network, Charlbury, UK; ${ }^{2}$ The BMJ, London, UK
}

The World Medical Association (WMA) has unanimously approved a statement on healthcare information for all, proposed by the British Medical Association. ${ }^{1}$ The statement notes that lack of access to timely, current, evidence based healthcare information continues to be a major contributor to morbidity and mortality, especially in low and middle income countries, and calls on doctors worldwide to support initiatives to improve access for health professionals, patients, and the public.

The BMJ hosted a conference on this issue in $1994^{2}$ and cofounded Hinari in 2001, a partnership between publishers and the World Health Organization to improve the availability of e-journals and e-books in low and middle income countries. ${ }^{3}$

In 2004 we coauthored a paper in the Lancet describing the global healthcare information system and its interdependent parts. ${ }^{4} \mathrm{We}$ called for a global campaign to support communication, understanding, and advocacy among all stakeholders. These include researchers, journal publishers, systematic reviewers, guideline developers, publishers of secondary materials (from textbooks to radio shows), those who guide and provide access (from search engines to librarians), and all who share the vision of a world where everyone has access to the information they need to protect their own and others' health. Healthcare Information For All (HIFA) now has 20000 members in 180 countries, interacting on six discussion forums in four languages and working closely with WHO, which states its "quintessential function is to ensure access to authoritative and strategic information on matters that affect people's health."

Over half the world's population can now access the internet, and mobile phones are becoming ubiquitous. But as connectivity increases, so too does vulnerability to misinformation-on all topics from Ebola virus disease (belief that it is not real contributing to killing of Ebola workers), to vaccination (MMR and vaccine hesitancy, conspiracy theories, and killing of polio vaccine workers), to family planning (countless myths about pregnancy and contraception), and most recently to coronavirus (belief that nasal rinsing with salt water will prevent infection). Health literacy is more important than ever-the capacity to obtain, process, and understand the healthcare information needed to make appropriate health decisions. ${ }^{6}$ Equally, providers of information should ensure their content meets the diverse literacy and language needs of users.

\section{Reality check}

Open access, open data, increased rigour in guideline development, and evidence informed policy and practice are rapidly changing the "upstream" components of the global healthcare information system, but the reality on the front lines of healthcare has changed relatively little. Thousands of children and adults continue to die needlessly every day because of failure to provide life saving interventions. Such interventions are often available locally but are not provided because of lack of healthcare information, resulting in indecision, delays, misdiagnosis, or incorrect treatment at all levels, from the home to the facility.

Hundreds of children die from diarrhoea every day in India alone, and almost all of these deaths are avoidable with simple rehydration. Yet, a recent health survey in India found that 57\% of children with diarrhoea in the previous two weeks had been given less to drink than usual and 5\% had been given nothing to drink at all. ${ }^{7}$ If an affected child reaches a health worker, they may inappropriately be given antibiotics rather than oral rehydration.

A similar picture is seen in other countries and across every area of health and disease. This is not the fault of care givers. Every parent and health worker wants to provide the best possible care, but they are disempowered by lack of access to reliable healthcare information. This is compounded by commercial interests and deliberate misinformation, leading inevitably to patient harm, waste of resources, and antimicrobial resistance. WHO noted in 2011 that "Globally, most prescribers receive most of their prescribing information from the pharmaceutical industry and in many countries this is the only information they receive." ${ }^{8}$ There is no evidence that this has changed.

Access to healthcare information is fundamental for achieving the health targets in the sustainable development goals: universal health coverage and health for all. Progress has been limited by a failure of political and financial support. This is why the new 
WMA statement is so important. Its seven recommendations provide the beginning of a framework for collective action (box).

\section{World Medical Association recommendations ${ }^{1}$}

The WMA and its constituent members on behalf of their physician members, will support and commit to the following actions:

- Promote initiatives to improve access to timely, current, evidence based healthcare information for health professionals, patients, and the public to support appropriate decision making, lifestyle changes, care seeking behaviour, and improved quality of care

- Promote standards of good practice and ethics to be met by information providers, guaranteeing reliable and quality information that is produced with the participation of physicians, other health professionals, and patient representatives

- Support research to identify enablers and barriers to the availability of healthcare information, including how to improve the production and dissemination of evidence based information for the public, patients, and health professionals and measures to increase health literacy and the ability to find and interpret such information

- Ensure that health professionals have access to evidence based information on diagnosis and treatment of diseases, including unbiased information on medicines. Particular attention should be paid to those working in primary care in low and middle income countries

- Combat myths and misinformation around healthcare through validated scientific and clinical evidence and by urging the media to report responsibly on health matters

- Urge governments to recognise their moral obligation to take measures to improve the availability and use of evidence based healthcare information

- Urge governments to provide the political and financial support needed for WHO's function to ensure access to authoritative and strategic information on matters that affect people's health, based on the WHO general programme of work 2019-23.

\section{Call to action}

Action is now needed to take these recommendations forward. HIFA plans to establish a multidisciplinary working group to assess, act, and monitor progress on each recommendation. The group will include representatives from WMA, the BMA and other national medical associations, WHO, and other providers and users of healthcare information.

We encourage everyone with an interest in the availability and use of healthcare information to visit the HIFA website (www. hifa.org), join the HIFA discussion forum (www.hifa.org/ joinhifa), and contact HIFA at admin@ hifa.org. Together, we can stop people dying because of lack of healthcare information.

Competing interests: We have read and understood BMJ policy on declaration of interests and declare NP-W helped BMA International Department to draft the original statement that was submitted to the WMA, and helped BMA International to respond to subsequent questions from national medical associations.

Provenance and peer review: Commissioned; not externally peer reviewed.

1 World Medical Association. WMA statement on healthcare information for all. Adopted by the 70th WMA General Assembly, Tbilisi, Georgia, October 2019. https://www.wma net/policies-post/wma-statement-on-healthcare-information-for-all/

2 Kale R. Health information for the developing world. BMJ 1994;309:939-42. 10.1136/bmj.309.6959.939. 7950670

3 Hinari. Access to research for health programme. https://www.who.int/hinari/en/

4 Godlee F, Pakenham-Walsh N, Ncayiyana D, Cohen B, Packer A. Can we achieve health information for all by 2015? Lancet 2004;364:295-300.

10.1016/S0140-6736(04)16681-6. 15262109

5 World Health Organization. Thirteenth general programme of work, 2019-2023. https:// apps.who.int/iris/bitstream/handle/10665/324775/WHO-PRP-18.1-eng.pdf

6 National Network of Libraries of Medicine. Health literacy definition. https://nnlm.gov/ initiatives/topics/health-literacy

7 Ministry of Health and Family Welfare Government of India. National Family Health Survey (NFHS-4) 2015/16. http://rchiips.org/nfhs/NFHS-4Reports/lndia.pdf

8 Holloway K, van Dijk L. The world medicines situation 2011: rational use of medicines. 2011. http://apps.who.int/medicinedocs/documents/s18064en/s18064en.pdf

Published by the BMJ Publishing Group Limited. For permission to use (where not already granted under a licence) please go to http://group.bmj.com/group/rights-licensing/ permissions 